\title{
Behavior of Native Food Isolates of Listeria monocytogenes and Listeria innocua under the Influence of Selected Cultural Attributes and Heat and Cold Treatments
}

\author{
Jayanth Sunderraj Hampapura ${ }^{1,2 *}$ (i) and Varadaraj Mandyam Chakravarathy ${ }^{1}$ \\ ${ }^{1}$ Department of Microbiology and Fermentation Technology, CSIR-Central Food Technological Research \\ Institute, Mysuru-570 020, Karnataka, India. \\ ${ }^{2}$ Department of Microbiology, Yuvaraja's College, University of Mysore, Mysuru-570 005, Karnataka, India.
}

\begin{abstract}
The present investigation assesses the influence of cultural attributes and heat and cold treatments on the behavior of native toxigenic L. monocytogenes CFR 1302 and non-toxigenic L. innocua CFR 1304 in selected medium. The growth responses of $L$. monocytogenes and $L$. innocua under the influencing factors of storage temperature $\left(10-40^{\circ} \mathrm{C}\right)$, $\mathrm{pH}$ level (5.5-7.5), and storage period (6-48 $\mathrm{h}$ ) in brain heart infusion and nutrient broths revealed closeness between observed and predicted populations. Response surface plots were generated for the growth behavior of the two test cultures as a function of pH level. The toxigenic L. monocytogenes CFR 1302 could reach a higher viable population. The effect of heat treatment on Listeria spp. in selected five heating menstra showed the lowest $D$-value of $3.7 \mathrm{~min}$ at $60^{\circ} \mathrm{C}$ for $L$. innocua CFR 1304 in Milli-Q water to the highest of $8.4 \mathrm{~min}$ at $56^{\circ} \mathrm{C}$ for L. monocytogenes CFR 1302 in skim milk. The average z-value across the heating menstra for L. monocytogenes was $27.3^{\circ} \mathrm{C}$ as against that of $22^{\circ} \mathrm{C}$ for $L$. innocua. In the case of cold treatment, storage of 4 and $8^{\circ} \mathrm{C}$ resulted in appreciable increase in counts of $L$. monocytogenes CFR 1302 from the initial inoculum introduced in selected media. At $-20^{\circ} \mathrm{C}$, there was a slight decrease in the viable population. The research data helps to predict the viable populations of $L$. monocytogenes as a part of risk assessment in the food chain. This is of significance in providing safe and healthy food to human population.
\end{abstract}

Keywords: Listeria monocytogenes, Listeria innocua, Growth responses, Influencing factors, Response surface plots, Heat treatment, Cold treatment, $D$-value

*Correspondence: hsjayanth@ycm.uni-mysore.ac.in; +91-9845137591

(Received: August 12, 2021; accepted: October 19, 2021)

Citation: Hampapura JS, Chakravarathy VM. Behavior of Native Food Isolates of Listeria monocytogenes and Listeria innocua under the Influence of Selected Cultural Attributes and Heat and Cold Treatments. J Pure Appl Microbiol. 2021;15(4):2209-2228. doi: 10.22207/JPAM.15.4.44

(C) The Author(s) 2021. Open Access. This article is distributed under the terms of the Creative Commons Attribution 4.0 International License which permits unrestricted use, sharing, distribution, and reproduction in any medium, provided you give appropriate credit to the original author(s) and the source, provide a link to the Creative Commons license, and indicate if changes were made. 


\section{INTRODUCTION}

The changing economic scenario of a progressive society has impacted the eating habits with processed foods becoming the order of the day. Microbes tend to be present in most type of foods, either plant or animal-based, but more alarming aspect is the microbial contaminants, particularly pathogenic species entering foods that could lead to health hazards..$^{1,2}$ Considering the increasing emphasis on microbial safety, one of the important public health concerns is associated with $L$. monocytogenes, a pathogen involved in the number of high-risk health hazards. The risk assessment report of $L$. monocytogenes has analyzed the causes of health hazards taking into consideration the overall food chain and documented the outlines of risk assessment. ${ }^{3}$

A model was established in mid- 2000 to monitor and assure the safety of chilled food products by using their time-temperature history and variations in characteristics like water activity, $\mathrm{pH}$, and predictive models of growth. ${ }^{4}$ The research findings of studies related to effect of water activity levels, $\mathrm{pH}$. incubation time-temperature, and food additives like sodium chloride, acidulants, and sodium nitrite on the growth behavior of $L$. monocytogenes was studied in different culture broths, skim milk, whey, and meat broth were analyzed and interpreted through predictive models. $^{5-8}$

In the background of food poisoning outbreaks caused by the presence of $L$. monocytogenes, the behavior of this organism under heat and cold treatments attains significance as these two factors operate in combination in the complete food chain establishment. Studies relating to heat resistance of $L$. monocytogenes in various heating menstra have been documented in literature with focus on higher temperatures and food-based substrates. ${ }^{9-14}$ At the same time, the ability of $L$. monocytogenes to survive or thrive at low temperatures, a characteristic of psychrophilic culture achieves greater significance in the food chain. ${ }^{15}$ Studies have been performed over a wide range of temperatures that includes deep freezing, frozen and refrigeration in buffered saline, culture broths and food-based substrates with constituents that could afford protection to the culture. ${ }^{16,12,17-19}$
As the consumer focus is on microbial food safety, use of multiple barriers to prevent potential health hazards arising out of food associated $L$. monocytogenes and other Listeria spp., there have been a few studies on the quantitative data that could be used to estimate the relative impact of factors that interact to influence growth behavior of Listeria spp. The temperatures encountered during food processing do affect the survival / growth of bacterial cultures. However, it is well known that strains of $L$. monocytogenes survive under adverse conditions over a considerable time period, after which the organism could proliferate and become a risk factor with respect to human health. Studies undertaken with the behavior of cultures would give additional knowledge that enable food chain to perform effectively. ${ }^{20}$

In the background of documented studies relating to growth kinetics of Listeria spp. in response to cultural attributes as well as heat and cold treatments with varying influencing factors / variables, it becomes important that studies on growth behavior need to be undertaken with cultures of $L$. monocytogenes harboring toxigenic traits and isolated from specific food habitats, as they could be a cause of risk under prevailing environmental conditions. Most of the earlier studies have been undertaken with an established toxigenic culture of L. monocytogenes Scott A while the behavioral pattern under the influencing factors are dealt with separately.

Considering microbial diversity in a wide range of food habits, it becomes important to assess the potential health risk that could result from the growth responses of an isolate of $L$. monocytogenes that could prevail in commonly consumed foods. Besides, it will be of great significance for food safety programmes to assess the behavior of pathogenic culture under the impact of those factors that are encountered in the food chain in total. Accordingly, the objective of the present study was to analyse the behavior of native toxigenic L. monocytogenes CFR 1302 and non-toxigenic L. innocua CFR 1304 in selected media / menstra under the influence of cultural attributes and heat / cold treatments that prevails in most of the food chain establishment. Considering the habitats of bacterial cultures in a given environment, the generated data would 
provide insight into the probability of such native isolates of $L$. monocytogenes to be the cause of health hazards under situations that could be favorable for the toxigenic culture.

\section{MATERIALS AND METHODS Pre-requisites}

Dry or wet sterilization was conducted for all glassware, media, and other materials used in the present study. Dry sterilization was carried out at $180^{\circ} \mathrm{C}$ for $4 \mathrm{~h}$ in a Hot Air Oven while wet sterilization was done at $121^{\circ} \mathrm{C}$ for $20 \mathrm{~min}$ in an autoclave. Dehydrated media was procured from Hi-Media Lab., Mumbai, India to prepare the bacteriological media for use as per manufacturer's instructions. Milli-Q water (A10 Elix 3, Millipore Corporation, Billerica, USA) was used as water in the experimental trials.

Bacterial cultures and inoculum preparation

These consisted (i) two native food isolates of Listeria monocytogenes CFR 1302 and Listeria innocua CFR 1304 procured from raw whole cow milk and (ii) reference culture of $L$. monocytogenes Scott A acquired by the courtesy of Dr. A.K. Bhunia of Purdue University, USA. The cultures were maintained on brain heart infusion agar slants in the culture stock of host laboratory at $4^{\circ} \mathrm{C}$. The cultures were grown successively twice in $\mathrm{BHI}$ broth for $24 \mathrm{~h}$ at $37^{\circ} \mathrm{C}$, prior to use in experimental trials. From a $20 \mathrm{~h}$ old $\mathrm{BHI}$ culture broth, cell suspensions of these cultures were individually prepared by centrifugation at 7200 $\mathrm{g}$ for $20 \mathrm{~min}$ in a refrigerated centrifuge at $4^{\circ} \mathrm{C}$ (Superspin R-V/FM, Plasto Crafts, Mumbai, India). The harvested cells were stored until further use after resuspension in sterile $10 \mathrm{ml}$ aliquots of $0.85 \%$ saline.

\section{Growth substrates / treatment menstra}

These included (i) Milli-Q water, (ii) brain heart infusion (BHI) broth, (iii) nutrient broth, (iv) phosphate buffer (PBS) $0.01 \mathrm{~mol} \mathrm{~L}^{-1}$, (iv) skim milk and (v) whole cow milk. The $\mathrm{BHI}$ and nutrient broths were that of dehydrated media and prepared according to manufacturer's guidelines. Phosphate buffer saline $\left(0.01 \mathrm{~mol} \mathrm{~L}^{-1}\right)$ was prepared following the method of USDFA. ${ }^{21} \mathrm{~A}$ stock solution was prepared having a concentration of $0.1 \mathrm{~mol}$ $\mathrm{L}^{-1}$ and for use in experimental trials, the stock solution was diluted in the ratio of 1:9 with Milli-Q water, $\mathrm{pH}$ adjusted to 7.5 and autoclaved for 15 min at $121^{\circ} \mathrm{C}$.

Skim milk was prepared by reconstituting requisite quantity of commercially available spray dried skim milk powder at a level of $10 \%$, filtered, dispensed in required quantities in appropriate glassware and autoclaved for $15 \mathrm{~min}$ at $121^{\circ} \mathrm{C}$. The pasteurized whole cow milk with $3 \%$ fat content obtained from the local commercial Dairy outlet was filtered using moistened cotton pad, dispensed in requisite quantities in appropriate glassware and autoclaved for $15 \mathrm{~min}$ at $121^{\circ} \mathrm{C}$.

Modeling the growth behavior of Listeria spp. in culture broth

In the background of environmental factors that would exist in the commercial food chain, few of these factors were selected for the experimental design. A central composite design based on three factors and five levels with storage temperatures of 10 to $40^{\circ} \mathrm{C}, \mathrm{pH}$ levels of 5.5 to 7.5 and storage periods of 6 to $48 \mathrm{~h}$ was used for experimental design. The experimental design included 21 treatments with 7 center point repeats. The culture media used were those of nutrient and BHI broths. The individual broth medium in $10 \mathrm{ml}$ quantity was inoculated with $0.1 \mathrm{ml}$ inoculum of individual cultures of L. monocytogenes CFR 1302 and L. innocua CFR 1304 to obtain the desired initial population level of $2.3 \log _{10} \mathrm{CFU} \mathrm{mL}$. . The broth tubes containing the inoculum were vortexed and incubated at specified time-temperature combinations as per the experimental design. Aliquots of $0.1 \mathrm{~mL}$ of the appropriate dilutions of experimental culture broths were surface plated on Listeria Oxford agar pre-poured plates. The inoculated plates were incubated for $24-48 \mathrm{~h}$ at $37^{\circ} \mathrm{C}$ and characteristic colonies of Listeria sp. formed in the incubated plates were counted and expressed as average $\log _{10}$ CFU mL-1.

Multivariate analysis was performed by subjecting experimental data relating to the viable counts of the above-mentioned two cultures of Listeria spp. and predictions of microbial behavior was achieved by partial least square regression. ${ }^{22}$ Microsoft Excel Software Programme 2010 (Microsoft Corporation, Redmond, WA, USA) 
was used to perform all calculations. The derived equation for individual cultures and culture broths studied was as follows:

$\mathrm{CFU}_{\text {prd }}=\mathrm{X}_{0}+\mathrm{X}_{1}(\mathrm{~T})+\mathrm{X}_{2}(\mathrm{P})+\mathrm{X}_{3}(\mathrm{t})+\mathrm{X}_{4}(\mathrm{~T})^{2}+\mathrm{X}_{5}(\mathrm{TxP})$ $+X_{6}(P)^{2}+X_{7}(P x t)+X_{8}(t)^{2}+X_{9}(t x T)$

Wherein $X_{0}$ was the intercept, $X_{1}-X_{9}$ were the coefficients, $T$ was storage temperature $\left({ }^{\circ} \mathrm{C}\right), \mathrm{P}$ was initial $\mathrm{pH}$ level of culture broth and $t$ was the storage period $(h)$. The significance and adequacy of the model was tested by subjecting the observed and predicted values to analysis of variance (ANOVA). The coefficient of determination $\left(R^{2}\right)$ value near to 1.0 indicates a good correlation between observed and predicted values and robustness of equation to derive model fits to predict growth kinetics of $L$. monocytogenes and $L$. innocua. Statistical significance was based on Fischer $(F)$ test. The values of $F(P<0.05)$ indicated that model terms are significant. The coefficients derived by multivariate analysis were utilized to generate response surface plots that could provide predictions for the populations of Listeria spp. over the range of variables within the experimental design.

\section{Effect of heat treatment on Listeria spp.}

Milli-Q water, BHI broth, $0.01 \mathrm{~mol} \mathrm{~L}^{-1} \mathrm{PBS}$, whole milk and skim milk were used as heating menstra in these experimental trials. Milli-Q water without any nutrients served as a control medium. Brain heart infusion broth routinely used for foodborne pathogenic bacterial organisms was used as a representative complex microbiological medium. Whole milk and skim milk were selected to serve as model heating medium with milk components including fat as simulating food matrix.

Vegetative cells of $L$. monocytogenes CFR 1302 and L. innocua CFR 1304 were thermally inactivated in test tubes $(15 \times 125 \mathrm{~mm})$ containing five $\mathrm{ml}$ of heating medium spiked with cells of individual test cultures at a level of $8.3 \log _{10}$ CFU $\mathrm{mL}^{-1}$. These inoculated tubes were placed in a temperature-controlled water bath. The test tubes were heated at pre-selected temperature of 56,58 and $60^{\circ} \mathrm{C}$, respectively, for specific time periods of 3, 6, 9, 12, 15 and $18 \mathrm{~min}$. Initially, appropriate come-up time for the contents of test tubes to attain the desired temperatures was calculated. The test tubes were removed once the specific time-temperature elapsed, after which they were cooled immediately in an ice-water bath. Appropriate dilutions of the experimental samples were enumerated for viable population of inoculated Listeria spp. as described previously. Plotting the $\log _{10}$ number of surviving cells for each time-temperature combination separately enabled in calculating the $D$-values (time in min to decrease the viable cell population by $90 \%$ ) using Microsoft Excel Software Programme 2010. Values in the straight position of derived curve were used for calculation. Regression analysis was used to determine the line-of-best fit for survivor plots. ${ }^{23} \mathrm{~A}$ regression equation was derived, of the form $y=a+b x$, wherein $b$ is the slope of the straight line whose inverted negative yields the $D$-value for a specific temperature ( $D=-1 /$ slope). A semi-logarithmic graph of $\log _{10} D$-values against respective temperatures was plotted and the negative inverse of the slope of thermal death time curve was calculated to derive the $z$-value i.e. $z$ value $=1 /$ slope. $^{24}$

Using OriginPro 6.1 software (OriginLab Corporation, Northampton, USA), significant difference in $D$-values among the two strains tested was performed by Duncan's New Multiple Range Test. One-way-analysis of variance of the average $D$-values of the two strains across heating menstra and temperatures as well as that with respect to strains and temperatures was performed. ${ }^{25}$

\section{Effect of cold treatment on Listeria spp.}

In this experimental study, the cultures selected were those of $L$. monocytogenes CFR 1302 and L. innocua CFR 1304. The effect of treatment was assessed in $\mathrm{BHI}$ broth, skim milk, and whole cow milk at 4,8 and $-20^{\circ} \mathrm{C}$, respectively, for specific duration of 2, 4, 6, 8 and 10 days. An initial inoculum of $5.4,6.4$, and $7.4 \log _{10}$ CFU $\mathrm{mL}^{-1}$ was obtained by inoculating pre-sterilized individual media in aliquots of $5 \mathrm{ml}$ each with 0.1 $\mathrm{ml}$ inoculum of respective cultures of Listeria spp. The inoculated tubes were kept at the selected temperatures in a BOD incubator (M.C. Dalal Company, Chennai, India). After the specified timetemperature treatments, appropriate dilutions of the experimental culture broths were enumerated for viable population of Listeria spp. as described previously. 
Table 1. Observed and predicted viable population of Listeria monocytogenes CFR 1302 in brain heart infusion broth and nutrient broth

\begin{tabular}{|c|c|c|c|c|c|c|}
\hline \multicolumn{2}{|c|}{ Factors / Variables } & \multicolumn{3}{|c|}{ Brain heart infusion broth } & \multicolumn{2}{|c|}{ Nutrient broth } \\
\hline $\begin{array}{l}\text { Storage } \\
\text { Temp. }\left({ }^{\circ} \mathrm{C}\right)\end{array}$ & $\begin{array}{c}\mathrm{pH} \\
\text { level }\end{array}$ & $\begin{array}{l}\text { Storage } \\
\text { period }(h)\end{array}$ & $\begin{array}{l}\text { Observed } \\
\text { Viable } \\
\text { population }\end{array}$ & $\begin{array}{l}\text { Predicted } \\
\left(\log _{10} \text { CFU }\right. \\
\left.\mathrm{mL}^{-1} \pm S E\right)\end{array}$ & Observed & Predicted \\
\hline 16 & 5.9 & 15 & $6.2 \pm 0.4$ & 6.4 & $4.8 \pm 0.2$ & 6.6 \\
\hline 34 & 5.9 & 15 & $9.0 \pm 0.3$ & 9.9 & $8.6 \pm 0.4$ & 19.1 \\
\hline 16 & 7.1 & 15 & $6.7 \pm 0.5$ & 6.6 & $5.8 \pm 0.3$ & 8.2 \\
\hline 34 & 7.1 & 15 & $9.3 \pm 0.4$ & 10.3 & $8.6 \pm 0.7$ & 18.8 \\
\hline 16 & 5.9 & 42 & $8.8 \pm 0.8$ & 10.2 & $7.6 \pm 0.4$ & 10.4 \\
\hline 34 & 5.9 & 42 & $8.6 \pm 0.3$ & 11.3 & $8.7 \pm 0.6$ & 20.4 \\
\hline 16 & 7.1 & 42 & $8.9 \pm 0.7$ & 10.4 & $8.6 \pm 0.7$ & 12.1 \\
\hline 34 & 7.1 & 42 & $9.2 \pm 0.4$ & 11.6 & $8.7 \pm 0.3$ & 20.3 \\
\hline 10 & 6.5 & 27 & $5.7 \pm 0.3$ & 6.7 & $4.1 \pm 0.4$ & 5.7 \\
\hline 40 & 6.5 & 27 & $8.8 \pm 0.6$ & 10.9 & $8.6 \pm 0.7$ & 23.1 \\
\hline 25 & 5.5 & 27 & $8.9 \pm 0.4$ & 10.3 & $8.2 \pm 0.4$ & 13.9 \\
\hline 25 & 7.5 & 27 & $9.2 \pm 0.9$ & 10.7 & $8.7 \pm 0.6$ & 15.1 \\
\hline 25 & 6.5 & 06 & $6.2 \pm 0.3$ & 7.2 & $6.7 \pm 0.3$ & 12.1 \\
\hline 25 & 6.5 & 48 & $9.0 \pm 0.5$ & 11.4 & $8.8 \pm 0.8$ & 16.3 \\
\hline 25 & 6.5 & 27 & $9.0 \pm 0.8$ & 10.2 & $8.6 \pm 0.5$ & 14.6 \\
\hline 25 & 6.5 & 27 & $9.1 \pm 0.4$ & 10.2 & $8.4 \pm 0.7$ & 14.6 \\
\hline 25 & 6.5 & 27 & $9.0 \pm 0.7$ & 10.2 & $8.6 \pm 0.3$ & 14.6 \\
\hline 25 & 6.5 & 27 & $9.0 \pm 0.6$ & 10.2 & $8.4 \pm 0.4$ & 14.6 \\
\hline 25 & 6.5 & 27 & $9.1 \pm 0.8$ & 10.2 & $8.6 \pm 0.8$ & 14.6 \\
\hline 25 & 6.5 & 27 & $9.0 \pm 0.4$ & 10.2 & $8.6 \pm 0.7$ & 14.6 \\
\hline 25 & 6.5 & 27 & $8.8 \pm 0.5$ & 10.2 & $8.5 \pm 0.5$ & 14.6 \\
\hline
\end{tabular}

$\mathrm{n}=3$; Values are the mean $\pm \mathrm{SE}$

\section{Statistical analysis}

Experimental trials were performed independently, in triplicates and the average values with standard errors presented in Tables or Figures. Microsoft Excel Programme, 2010, was used to make all calculations and statistical analyses (Microsoft Corporation, Redmond, WA, USA).

\section{RESULTS}

Growth behavior of Listeria spp. in culture broths

Considering the health-related risk associated with cultures of L. monocytogenes, an experimental study was undertaken to assess the growth proliferation ability of native food isolates of L. monocytogenes CFR 1302 and L. innocua CFR 1304 in two commonly culture broths using lower initial inoculum of $2.3 \log _{10}$ CFU $\mathrm{mL}^{-1}$. The influencing factors and their variables were selected simulating the prevailing global conditions of food chain system. The observed and predicted populations of L. monocytogenes CFR 1302 and L. innocua CFR 1304 in the two culture broths were presented in Tables 1 and 2 . In the design of 21 experimental sets, the counts reached by $L$. monocytogenes in $\mathrm{BHI}$ broth was around $9.0 \log _{10} \mathrm{CFU} \mathrm{mL} \mathrm{mL}^{-1}$, except in four treatment sets, the counts ranged between 5.7 and $6.7 \log _{10}$ CFU $\mathrm{mL}^{-1}$ (Table 1$)$. The storage period of more than $15 \mathrm{~h}$ did enable the culture to reach higher population. A lower temperature of $10^{\circ} \mathrm{C}$ was not able to support faster growth proliferating ability of the test culture. The predicted counts were quite close to that of observed counts. A similar growth profile of L. monocytogenes was observed in nutrient broth. However, the viable populations recorded were lower than those in $\mathrm{BHI}$ broth. The higher population was around $8.8 \log _{10} \mathrm{CFU} \mathrm{mL}-1$. The lower population was in the range of 4.1-6.7 $\log _{10}$ CFU mL $\mathrm{mL}^{-1}$ (Table 1). The predicted counts in 
Table 2. Observed and predicted viable population of Listeria innocua CFR 1304 in brain heart infusion broth and nutrient broth.

\begin{tabular}{|c|c|c|c|c|c|c|}
\hline \multicolumn{2}{|c|}{ Factors / Variables } & \multicolumn{3}{|c|}{ Brain heart infusion broth } & \multicolumn{2}{|c|}{ Nutrient broth } \\
\hline $\begin{array}{l}\text { Storage } \\
\text { Temp. }\left({ }^{\circ} \mathrm{C}\right)\end{array}$ & $\begin{array}{c}\mathrm{pH} \\
\text { level }\end{array}$ & $\begin{array}{l}\text { Storage } \\
\text { period (h) }\end{array}$ & $\begin{array}{l}\text { Observed } \\
\text { Viable } \\
\text { population }\end{array}$ & $\begin{array}{l}\text { Predicted } \\
\left(\log _{10} \text { CFU }\right. \\
\left.\mathrm{mL}^{-1} \pm S E\right)\end{array}$ & Observed & Predicted \\
\hline 16 & 5.9 & 15 & $5.0 \pm 0.3$ & 5.3 & $5.0 \pm 0.4$ & 4.2 \\
\hline 34 & 5.9 & 15 & $8.6 \pm 0.6$ & 8.9 & $7.9 \pm 0.6$ & 6.8 \\
\hline 16 & 7.1 & 15 & $5.6 \pm 0.4$ & 5.9 & $5.5 \pm 0.5$ & 4.6 \\
\hline 34 & 7.1 & 15 & $9.2 \pm 0.7$ & 9.6 & $8.2 \pm 0.3$ & 7.5 \\
\hline 16 & 5.9 & 42 & $8.5 \pm 0.6$ & 10.8 & $8.2 \pm 0.6$ & 6.9 \\
\hline 34 & 5.9 & 42 & $9.0 \pm 0.5$ & 11.5 & $7.8 \pm 0.3$ & 6.6 \\
\hline 16 & 7.1 & 42 & $8.7 \pm 0.7$ & 11.4 & $7.8 \pm 0.4$ & 6.9 \\
\hline 34 & 7.1 & 42 & $9.3 \pm 0.9$ & 12.1 & $8.1 \pm 0.7$ & 6.8 \\
\hline 10 & 6.5 & 27 & $4.8 \pm 0.3$ & 6.8 & $5.0 \pm 0.2$ & 5.1 \\
\hline 40 & 6.5 & 27 & $9.0 \pm 0.6$ & 10.7 & $8.2 \pm 0.4$ & 7.5 \\
\hline 25 & 5.5 & 27 & $9.0 \pm 0.4$ & 10.5 & $7.6 \pm 0.6$ & 7.5 \\
\hline 25 & 7.5 & 27 & $9.2 \pm 0.5$ & 11.5 & $8.5 \pm 0.5$ & 8.1 \\
\hline 25 & 6.5 & 06 & $4.2 \pm 0.2$ & 5.1 & $3.5 \pm 0.3$ & 4.1 \\
\hline 25 & 6.5 & 48 & $9.2 \pm 0.7$ & 12.0 & $8.1 \pm 0.9$ & 6.3 \\
\hline 25 & 6.5 & 27 & $9.2 \pm 0.5$ & 10.8 & $7.9 \pm 0.4$ & 7.4 \\
\hline 25 & 6.5 & 27 & $9.2 \pm 0.9$ & 10.8 & $7.9 \pm 0.7$ & 7.4 \\
\hline 25 & 6.5 & 27 & $9.2 \pm 0.6$ & 10.8 & $8.2 \pm 0.6$ & 7.4 \\
\hline 25 & 6.5 & 27 & $9.2 \pm 0.8$ & 10.8 & $8.2 \pm 0.8$ & 7.4 \\
\hline 25 & 6.5 & 27 & $9.2 \pm 0.6$ & 10.8 & $8.2 \pm 0.6$ & 7.4 \\
\hline 25 & 6.5 & 27 & $9.2 \pm 0.5$ & 10.8 & $8.0 \pm 0.5$ & 7.4 \\
\hline 25 & 6.5 & 27 & $9.2 \pm 0.7$ & 10.8 & $8.1 \pm 0.3$ & 7.4 \\
\hline
\end{tabular}

$\mathrm{n}=3$; Values are the mean $\pm \mathrm{SE}$

case of nutrient broth were quite variable with exceedingly higher counts being predicted in most of the treatment codes. In BHI broth, the culture of L. innocua CFR 1304 exhibited similar growth profile to that of $L$. monocytogenes with lower counts 4.2-5.6 $\log _{10}$ CFU mL ${ }^{-1}$ in four treatment sets (Table 2). However, in nutrient broth, the predicted counts were in close proximity with those of observed counts as against the highly variable predicted counts of L. monocytogenes. However, in nutrient broth, the counts were slightly lower, except for higher counts of $8.0 \log _{10} \mathrm{CFU} \mathrm{mL} \mathrm{m}^{-1}$. The predicted counts were in close proximity with those of observed counts as against the variable predicted counts of L. monocytogenes CFR 1302 in nutrient broth (Table 1).

A polynomial regression equation was derived for the individual cultures of $L$. monocytogenes CFR 1302 and L. innocua CFR 1304 in culture broths by subjecting the generated experimental data to multivariate analysis. The derived coefficients in culture broths for these two respective cultures are presented in Tables 3 and 4. The $R^{2}$ values for the derived equations were in the range of 0.87 to 0.98 indicating the effectiveness of equation to derive response surface plots. Although these appeared to be certain good agreement under certain experimental parameters of the central composite design, it was also observed that derived predictions of few other treatment sets were variable. However, the populations recorded with the experimental trials were quite lower than the predicted counts that signifies margin of safety in generating curve fittings. It appears that growth behavior of $L$. monocytogenes CFR 1302 and L. innocua CFR 1304 in $\mathrm{BHI}$ and nutrient broths was primarily influenced by storage temperature and time period as many of the model parameters were not statistically significant $(P<0.05)$.

In order to generate the response surface plots for the growth behavior of $L$. monocytogenes 
CFR 1302 and L. innocua CFR 1304 as a function of $\mathrm{pH}$ level, the coefficients derived by multivariate analysis were utilized. The derived quadratic responses for the two cultures of Listeria spp. included in present study were as follows:

Listeria monocytogenes CFR 1302 in (i)

$\mathrm{BHI}$ and (ii) nutrient broths

(i) $\mathrm{CFU} \log _{10}=7.91+0.52 \mathrm{~T}-3.94 \mathrm{P}+0.34 \mathrm{t}$ $-0.006 \mathrm{~T}^{2}-0.006 \mathrm{TxP}+0.31 \mathrm{P}^{2}-0.0009 \mathrm{Pxt}-$ $0.002 t^{2}-0.005 t x T$

(ii) CFU $\log _{10}=-29.76+1.32 \mathrm{~T}+4.26 \mathrm{P}+0.26 \mathrm{t}$ $-0.009 T^{2}-0.085 T x P-0.125 P^{2}+0.003 P x t-$ $0.001 t^{2}-0.005 t x T$

Listeria innocua CFR 1304 in (i) BHI and

(ii) nutrient broths

(i) $\mathrm{CFU} \log _{10}=-3.91+0.72 \mathrm{~T}-2.37 \mathrm{P}+0.58 \mathrm{t}$ $-0.008 T^{2}+0.002 T x P+0.218 P^{2}-0.009 P x t-$ $0.005 \mathrm{t}^{2}-0.006 \mathrm{txT}$

(ii) $\mathrm{CFU} \log _{10}=4.44+0.42 \mathrm{~T}-3.87 \mathrm{P}+0.56 \mathrm{t}$ $-0.004 T^{2}+0.011 T x P+0.328 P^{2}-0.014 P x t-$ $0.004 t^{2}-0.005 t x T$

As the response surface plots were in a similar manner, only representative surface plots at $\mathrm{pH}$ 6.0, 6.5 and 7.0 are presented for the two individual cultures in respective culture broths. The derived response surface plots for L. monocytogenes CFR 1302 in $\mathrm{BHI}$ and nutrient broths at selected $\mathrm{pH}$ levels are shown in Fig. 1 and 2 , respectively.

The response surface plot generated for L. monocytogenes CFR 1302 in BHI broth revealed that growth proliferation was almost same at all the $3 \mathrm{pH}$ levels presented. The risk population of 7.0 logs and above was evident with early storage periods of even $6 \mathrm{~h}$ at storage temperatures of $25^{\circ} \mathrm{C}$ and above. In the range of $10-20^{\circ} \mathrm{C}$, the same risk population level appears between 18-30 h of storage time. The maximum population level that could be visualized was 11.0 logs (Fig. 1). The growth profile in nutrient broth was similar to the one generated in $\mathrm{BHI}$ broth. However, the population levels were on a higher side, which may be uncharacteristic in a given experimental design. The derived population levels were similar to the predicted counts recorded in the CCRD experiment (Fig. 2 and Table 1).

The growth profile of L. innocua CFR 1304 in $\mathrm{BHI}$ broth visualized in the generated response surface plot was not in uniform pattern (Fig. 3). At all the storage temperatures, in the storage periods of 6-30 $\mathrm{h}$, the population levels were less than $1.0 \mathrm{log}$, followed by an increase and an immediate decrease and subsequently showing an increasing trend. The risk level of 7.0 log and above was evident at longer storage periods of 36-48 $\mathrm{h}$ at storage temperatures of $25-40^{\circ} \mathrm{C}$ (Fig. 3). On the other hand, L. innocua CFR 1304 in nutrient broth revealed lower population levels. Irrespective of $3 \mathrm{pH}$ levels (6.0, 6.5 and 7.0), the risk level of 7.0 log was evident only at stipulated storage periods of $18-42 \mathrm{~h}$ at storage temperatures of $20-40^{\circ} \mathrm{C}$ (Fig. 4).

Table 3. Coefficients derived by regression analysis for viable counts of Listeria monocytogenes CFR 1302 in brain heart infusion and nutrient broths, respectively

\begin{tabular}{|c|c|c|c|c|c|c|}
\hline \multirow[t]{2}{*}{ Source } & \multicolumn{3}{|c|}{ Brain heart infusion broth } & \multicolumn{3}{|c|}{ Nutrient broth } \\
\hline & Coefficient & SE & $P$ & Coefficient & SE & $P$ \\
\hline Intercept & 7.91 & 10.36 & 0.46 & 29.76 & 6.47 & 0.0007 \\
\hline $\mathrm{T}$ & 0.52 & 0.14 & 0.003 & 1.32 & 0.08 & $1.24 \mathrm{E}-08$ \\
\hline$P$ & -3.94 & 2.97 & 0.21 & 4.26 & 1.85 & 0.04 \\
\hline $\mathrm{t}$ & 0.34 & 0.09 & 0.004 & 0.26 & 0.05 & 0.001 \\
\hline $\mathrm{T}^{2}$ & -0.006 & 0.001 & $3.58 \mathrm{E}-05$ & -0.009 & 0.0006 & 7.64E-09 \\
\hline$T \times P$ & -0.006 & 0.02 & 0.73 & -0.08 & 0.01 & $2.94 \mathrm{E}-05$ \\
\hline$P^{2}$ & 0.31 & 0.22 & 0.19 & -0.12 & 0.13 & 0.38 \\
\hline$P \times t$ & -0.000 & 0.01 & 0.94 & 0.003 & 0.008 & 0.71 \\
\hline$t^{2}$ & -0.002 & 0.0004 & 0.0002 & -0.001 & 0.0003 & 0.0001 \\
\hline$t \times T$ & -0.005 & 0.0008 & 7.01E-05 & -0.005 & 0.0005 & $1.26 \mathrm{E}-06$ \\
\hline $\mathrm{R}^{2}$ & 0.96 & & & & 0.99 & \\
\hline
\end{tabular}

$\mathrm{T}$, storage temperature $\left({ }^{\circ} \mathrm{C}\right) ; \mathrm{P}, \mathrm{pH}$ level; $\mathrm{t}$, storage period $(\mathrm{h}) ; \mathrm{R}^{2}$, Coefficient of determination 
Effect of heat and cold treatments on Listeria spp.

In the experimental study, the viable cell numbers obtained after heat treatment in respect of L. monocytogenes CFR 1302 and L. innocua CFR 1304 in heating menstra of Milli-Q water, PBS, $\mathrm{BHI}$ broth, whole milk and skim milk were used to determine the $D$-values (time in $\mathrm{min}$ ), individually. A survivor curve generated for L. monocytogenes
CFR 1302 in Milli-Q water at $60^{\circ} \mathrm{C}$ is presented graphically (Fig. 5a) as a representative of determination of $D$-value. The survival curve plotted was linear with a correlation coefficient $\left(R^{2}\right)$ of above 0.90 . The $12 D$-values of the two test cultures and their corresponding decimal reduction time in selected heating menstra are shown in Table 5 . The $D$-values for these two

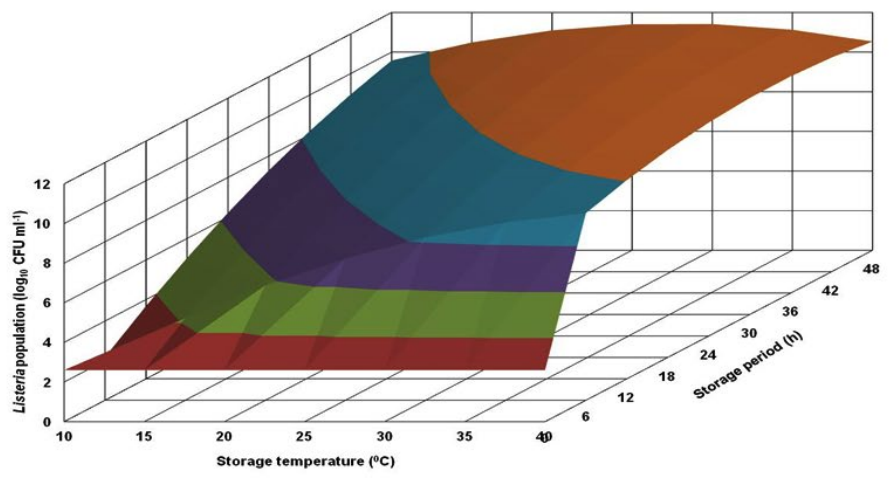

(a)

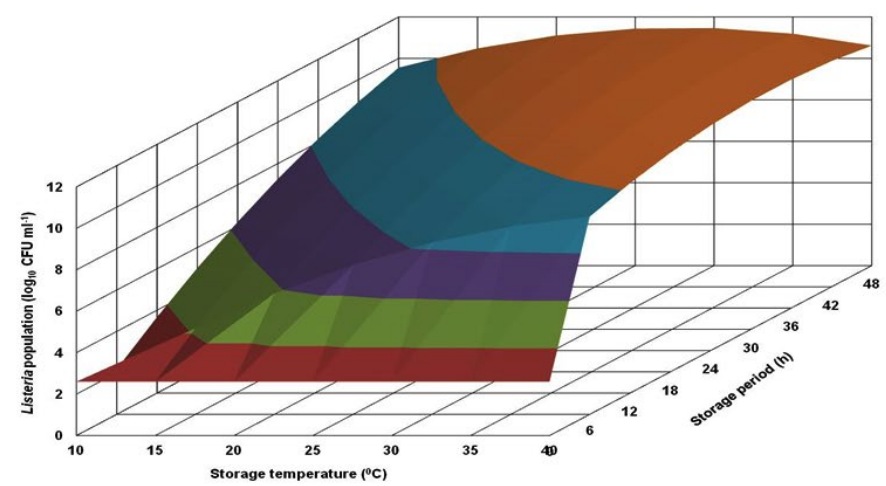

(b)

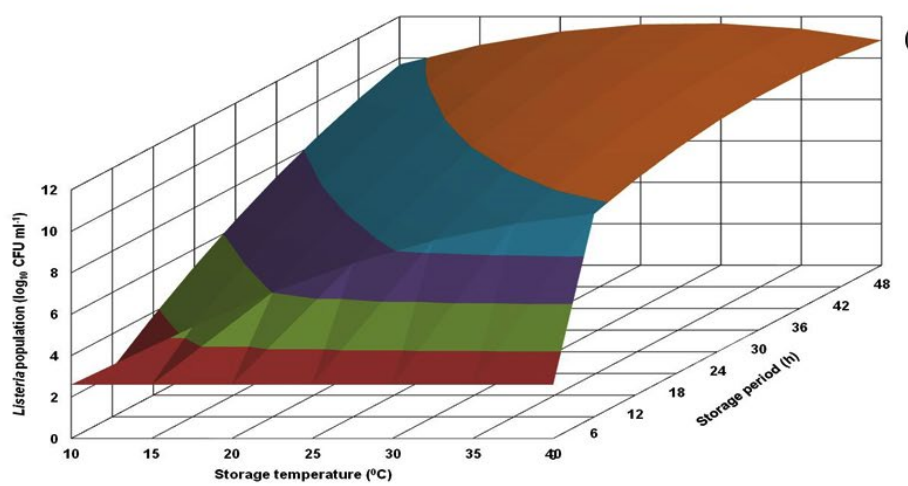

(c)

Fig. 1. Response surface plots for population of Listeria monocytogenes CFR 1302 grown in brain heart infusion broth at $\mathrm{pH}$ levels of 6.0 (a), 6.5 (b) and 7.0 (c). 
cultures ranged from a highest of $8.4 \mathrm{~min}$ at $56^{\circ} \mathrm{C}$ for L. monocytogenes CFR 1302 in skim milk to the lowest of $3.7 \mathrm{~min}$ at $60^{\circ} \mathrm{C}$ for L. innocua CFR 1304
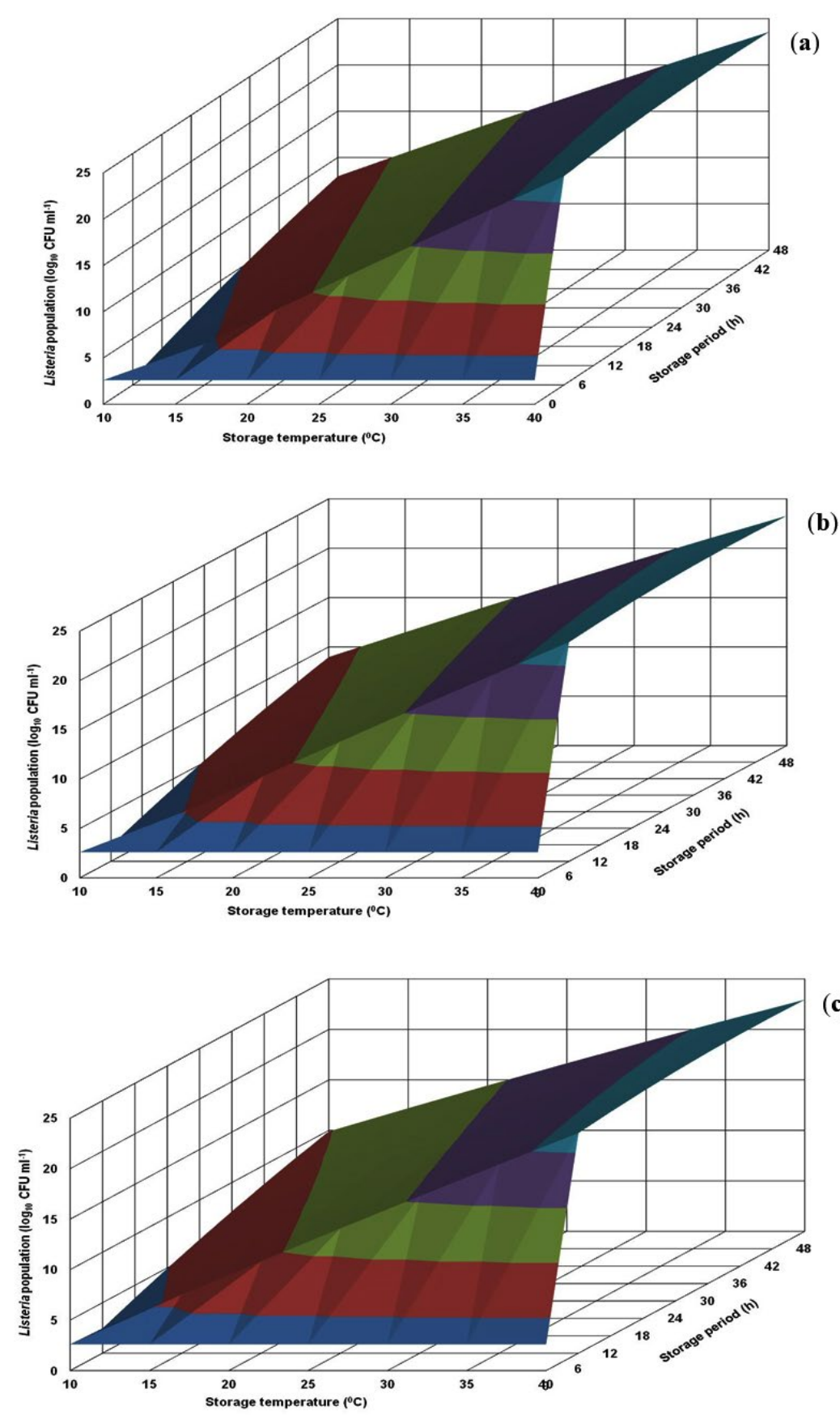

(a)

(b) in Milli-Q water. The commercial sterility values, also known as $12 D$-values, revealed a highest of $100.8 \mathrm{~min}$ to a lowest of $44.4 \mathrm{~min}$, all of which

(c)

Fig. 2. Response surface plots for population of Listeria monocytogenes CFR 1302 grown in nutrient broth at $\mathrm{pH}$ levels of 6.0 (a), 6.5 (b) and 7.0 (c). 
corresponded to the recorded $D$-values described previously. The average $12 D$-values at $60^{\circ} \mathrm{C}$ (near to pasteurization temperature) from all the five different heating menstra for L. monocytogenes CFR 1302 was 51.4 min which appeared to be in close agreement of time-temperature combination of conventional pasteurization of low temperature long time at $63^{\circ} \mathrm{C}$ for $30 \mathrm{~min}$. Tested across temperatures and the media, the mean $D$-values were 5.2 and 5.3 for L. monocytogenes CFR 1302 and L. innocua CFR 1304, respectively, which was statistically at par (Fig. 5b). There is clear indication, therefore, that the thermal resistance of these two cultures did not vary. From the derived mean $D$-values, it can be observed that the different heating menstra bore no varied influence $(P<0.05)$ upon the behavior of these two cultures against the heat treatment affected in this experimental study (Fig. 5c). These values were statistically not significant $(P<0.05)$, which goes to indicate that cultures of $L$. monocytogenes and $L$. innocua were not very much sensitive to heat treatments.

The $z$-values (the value of an increase in temperature required to reduce the $D$-value by one log) for the two test cultures are shown in Table 6. The lowest z-value of $14.2^{\circ} \mathrm{C}$ was recorded for L. innocua CFR 1304 in Milli-Q water and the highest of $33.3^{\circ} \mathrm{C}$ in whole milk was recorded for both $L$. monocytogenes and $L$. innocua. The average z-value for L. monocytogenes CFR 1302 was $27.3^{\circ} \mathrm{C}$ as against that of $22^{\circ} \mathrm{C}$ for L. innocua CFR 1304 across the heating menstra. The z-values for different heating media tested were statistically different for each of the test cultures. In the case of $L$. monocytogenes, the effect with PBS and skim milk was significant $(P<0.05)$, while it was not significant $(P<0.05)$ with Milli-Q water, $\mathrm{BHI}$ broth and whole milk. On the contrary, the effect with L. innocua CFR 1304 was statistically significant $(P<0.05)$.

The behavior of two native food isolates one each of toxigenic L. monocytogenes CFR 1302 (Fig. 6) and non-toxigenic L. innocua CFR 1304 (Fig. 7) to individual low temperatures of 4,8 and $-20^{\circ} \mathrm{C}$ was studied in selected media of BHI broth, skim milk and whole milk. At 4 and $8^{\circ} \mathrm{C}$ storage temperatures, the first viable populations of L. monocytogenes CFR 1302 in BHI broth, skim milk and whole milk demonstrate a considerable increase while in the storage period of $10 \mathrm{~d}$, except with an initial inoculum of $7.4 \mathrm{log}$ in whole milk at $8^{\circ} \mathrm{C}$. Irrespective of culture media, the highest counts recorded at $10 \mathrm{~d}$ storage period ranged between 6.7 and $8.9 \log _{10} \mathrm{CFU} \mathrm{mL}^{-1}$. However, there was a slight reduction in the viable population of L. monocytogenes CFR 1302 from the initial level during $10 \mathrm{~d}$ storage period in all three media when stored at $-20^{\circ} \mathrm{C}$ (Fig. 6). The viable counts recorded in $10 \mathrm{~d}$ storage ranged from 3.8-7.2 $\log _{10} \mathrm{CFU} \mathrm{ml^{-1 }}$ with an appreciable decrease with initial level of $5.4 \mathrm{log}$. The behavior of L. innocua CFR 1304

Table 4. Coefficients derived by regression analysis for viable counts of Listeria innocua CFR 1304 in brain heart infusion and nutrient broths, respectively

\begin{tabular}{|c|c|c|c|c|c|c|}
\hline \multirow[t]{2}{*}{ Source } & \multicolumn{3}{|c|}{ Brain heart infusion broth } & \multicolumn{3}{|c|}{ Nutrient broth } \\
\hline & Coefficient & SE & $P$ & Coefficient & SE & $P$ \\
\hline Intercept & -3.91 & 13.82 & 0.78 & 4.44 & 16.80 & 0.79 \\
\hline $\mathrm{T}$ & 0.72 & 0.19 & 0.002 & 0.42 & 0.23 & 0.09 \\
\hline$P$ & -2.37 & 3.97 & 0.56 & -3.87 & 4.82 & 0.43 \\
\hline $\mathrm{t}$ & 0.58 & 0.12 & 0.0006 & 0.56 & 0.15 & 0.003 \\
\hline $\mathrm{T}^{2}$ & -0.008 & 0.001 & $3.65 \mathrm{E}-05$ & -0.004 & 0.001 & 0.01 \\
\hline$T \times P$ & 0.002 & 0.02 & 0.93 & 0.01 & 0.03 & 0.72 \\
\hline$P^{2}$ & 0.21 & 0.29 & 0.47 & 0.32 & 0.36 & 0.38 \\
\hline$P \times t$ & -0.009 & 0.01 & 0.59 & -0.014 & 0.02 & 0.51 \\
\hline$t^{2}$ & -0.005 & 0.0006 & $9.52 \mathrm{E}-06$ & -0.004 & 0.0007 & 0.0001 \\
\hline$t \times T$ & -0.006 & 0.001 & 0.0002 & -0.005 & 0.001 & 0.001 \\
\hline $\mathrm{R}^{2}$ & 0.94 & & & & 0.87 & \\
\hline
\end{tabular}

$\mathrm{T}$, storage temperature $\left({ }^{\circ} \mathrm{C}\right) ; \mathrm{P}, \mathrm{pH}$ level; $\mathrm{t}$, storage period $(\mathrm{h}) ; \mathrm{R}^{2}$, Coefficient of determination 
was almost similar to that of $L$. monocytogenes, except in that the viable populations reached in $10 \mathrm{~d}$ storage was on a higher side at 4 and $8^{\circ} \mathrm{C}$ in the range of 6.8-9.4 $\log _{10} \mathrm{CFU} \mathrm{mL} \mathrm{m}^{-1}$ from their respective initial population levels. At $-20^{\circ} \mathrm{C}$
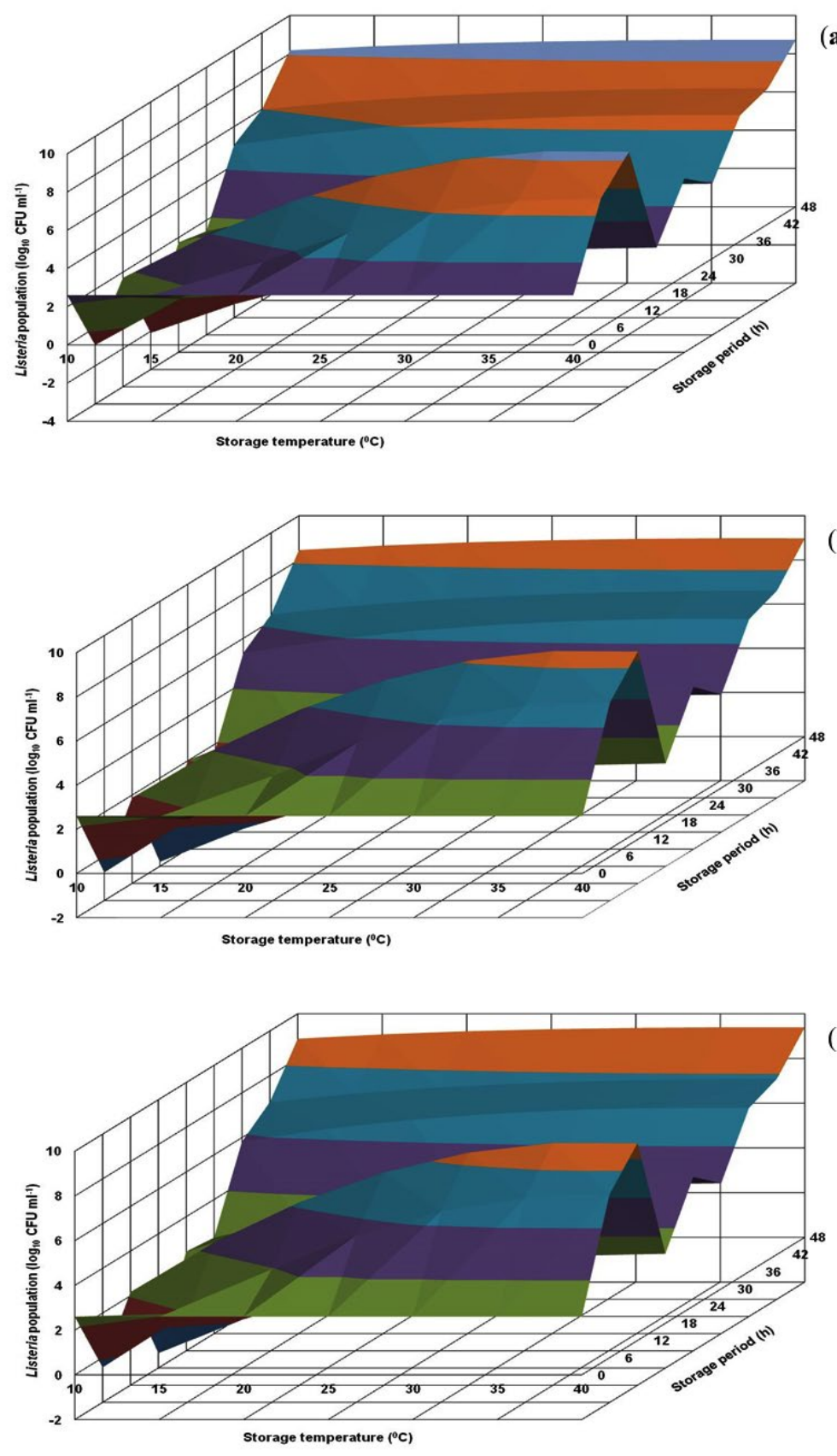

Fig. 3. Response surface plots for population of Listeria innocua CFR 1304 grown in brain heart infusion broth at $\mathrm{pH}$ levels of 6.0 (a), 6.5 (b) and 7.0 (c).

storage, the viable populations showed a marginal decrease of almost $1.0 \mathrm{log}$ in $10 \mathrm{~d}$ storage from their respective initial inoculum levels (Fig. 7) in all the three media. 


\section{DISCUSSION}

Growth responses of Listeria spp.

Most of the studies with L. monocytogenes have focused on the growth behavior of $L$. monocytogenes, on L. monocytogenes Scott A strain in different growth media. These studies have provided data that have an impact on food safety related aspects that can find commercial

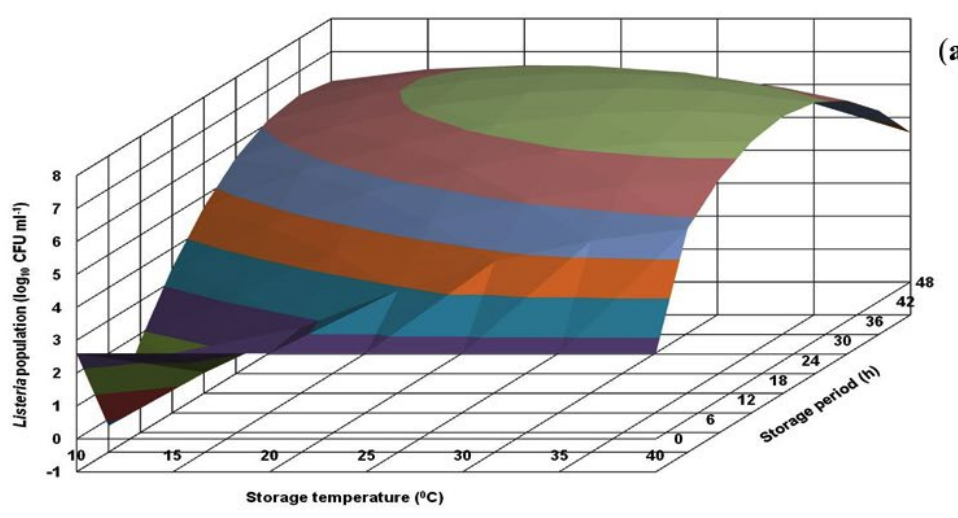

(a)

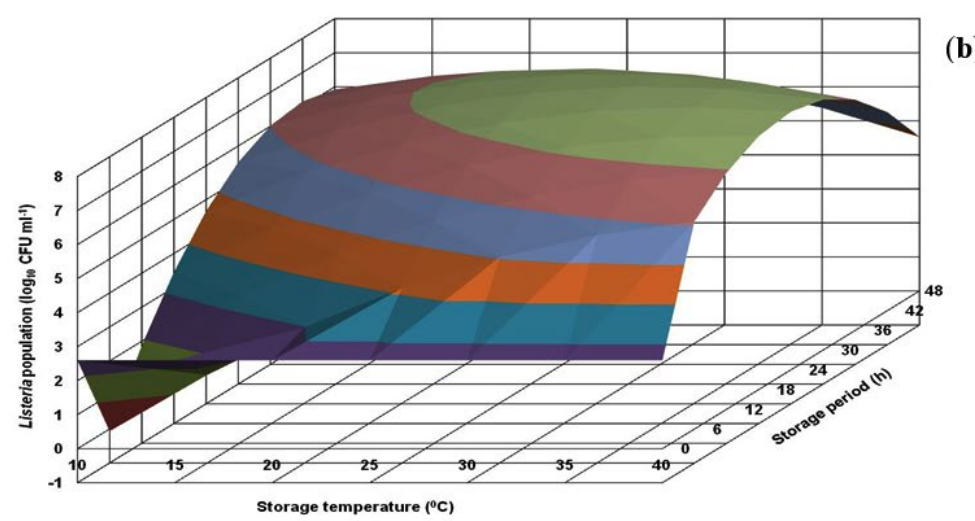

(b)

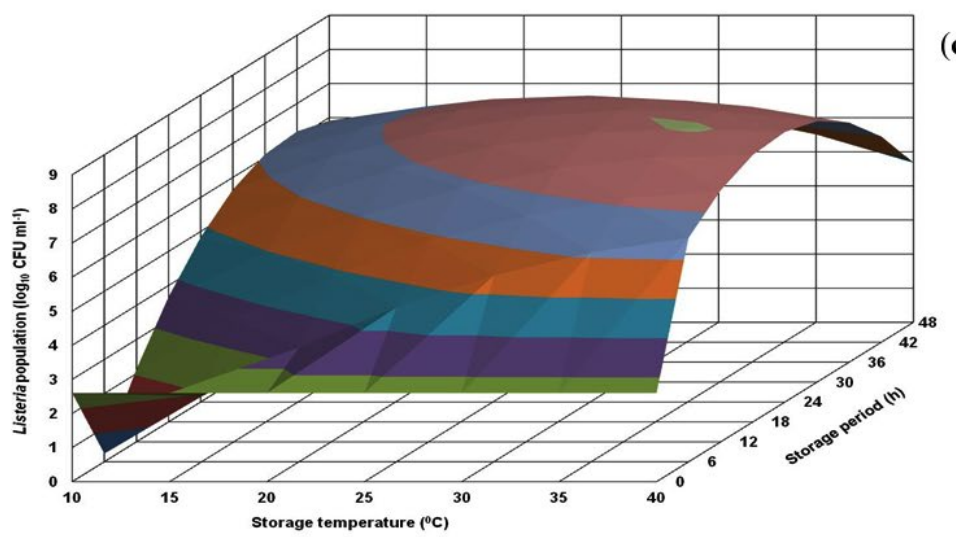

(c)

Fig. 4. Response surface plots for population of Listeria innocua CFR 1304 grown in nutrient broth at pH levels of $6.0(\mathrm{a}), 6.5$ (b) and 7.0 (c). 


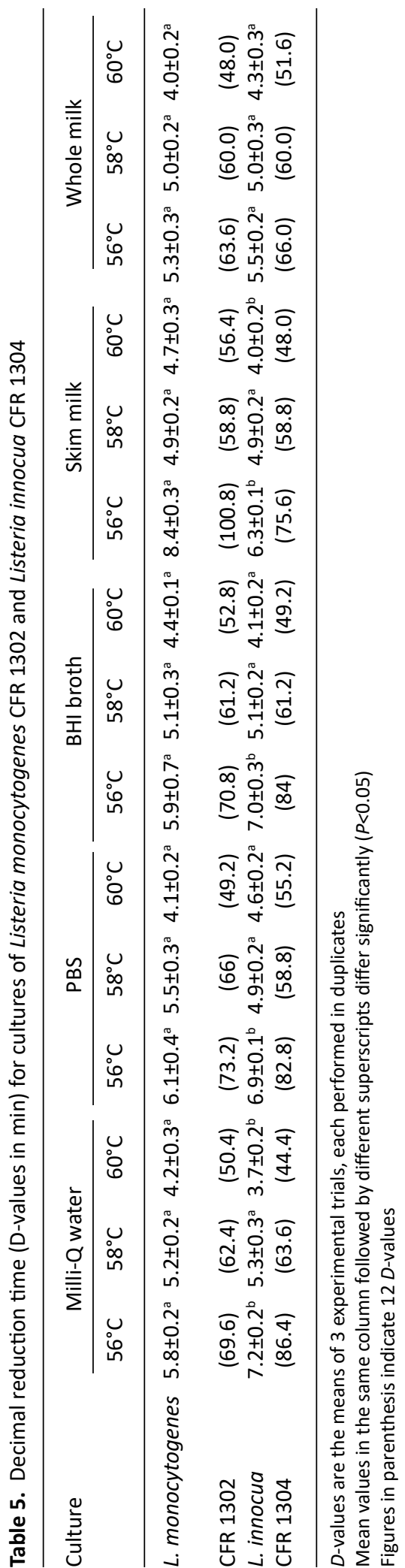

applications at different periods of time. Variation in growth responses have been attributed to the typical characteristics of specific culture influenced by environmental factors ${ }^{26}$. Considering the public health significance of $L$. monocytogenes, it becomes important to relate their behavior under probable extrinsic and intrinsic conditions that could prevail in the food chain system.

Considering the specificity of isolated culture in relation to the natural habitat and harboring of toxigenic traits, the present study was an attempt to evaluate the behavior of two native food isolates, one each of toxigenic $L$. monocytogenes CFR 1302 and a non-toxigenic L. innocua CFR 1304 introduced at minimum inoculum levels in two commonly used culture broths under the influence of storage temperature and periods, as well as $\mathrm{pH}$ levels that exist in the food chain at all times. It was observed that the risk causing population levels of $L$. monocytogenes were predominant under a wide range of cultural attributes generally encountered in the food chain. Earlier studies were undertaken on similar lines of present study to assess growth behavior of L. monocytogenes as influenced by cultural attributes and environmental factors. Response surface models generated using regression analysis revealed reasonable impact of influencing factors on the prolific growth of L. monocytogenes. ${ }^{5}$ Further, studies indicated that behavior of $L$. monocytogenes was more dependent on the type of strain and interactions of influencing factors, wherein growth responses varied among strains and this variation was mainly due to the type of culture and temperature effects. ${ }^{26,27}$

The present study did highlight that inoculum size was important in growth initiation. Under the effect of $\mathrm{pH}$ water activity, temperature, and the inoculum size in tryptic soy broth, the model revealed the importance of inoculum size for microbial growth initiation. ${ }^{6} \mathrm{~A}$ model proposed to predict the individual cell lag time of L. monocytogenes in different growth conditions was of importance in developing risk free food safety programme. ${ }^{28}$ Studies have been undertaken on other species of Listeria apart from $L$. monocytogenes, namely on $L$. seeligeri, L. innocua, L. ivanovi and L. welshimeri to generate growth estimates in response to variables of food and environment. ${ }^{29}$ 
Table 6. z-values of Listeria monocytogenes CFR 1302 and Listeria innocua CFR 1304 in different heating menstra

\begin{tabular}{lccccc}
\hline Culture & Heating menstra & & & \\
\hline & $\begin{array}{c}\text { Milli-Q } \\
\text { water } \\
\text { (Mean value }\end{array}$ & $\begin{array}{c}\text { Phosphate } \\
\text { buffered saline } \\
\text { in }{ }^{\circ} \mathrm{C} \pm \mathrm{SE} \text { ) }\end{array}$ & $\begin{array}{c}\text { BHI } \\
\text { broth }\end{array}$ & $\begin{array}{c}\text { Skim } \\
\text { milk }\end{array}$ & Whole \\
& $33.3 \pm 0.8$ & $20.0 \pm 0.9$ & $33.0 \pm 0.7$ & $16.6 \pm 1.2$ & $33.3 \pm 0.9$ \\
L. monocytogenes CFR 1302 & $14.2 \pm 1.1$ & $25.0 \pm 1.7$ & $16.6 \pm 1.1$ & $21.2 \pm 0.9$ & $33.3 \pm 1.7$ \\
L. innocua CFR 1304 & & & & & \\
\hline
\end{tabular}

Values across the media were statistically varied $(P<0.05)$

It was quite evident that effectiveness of response surface models those generated in present study as well as those of earlier researchers was more predominantly dependent on closeness of predicted data with that of experimental values. The predictions and surface plots generated in this study do indicate a safety margin, wherein that such population levels could be attained by bacterial cultures under extreme abuse conditions of post-processing contamination and handling practices in the food chain. The developed models could be more useful in describing growth limits of pathogens like L. monocytogenes in formulating food safety programmes

Effect of heat and cold treatments on Listeria spp.

As $L$. monocytogenes is involved in several food poisoning outbreaks, the behaviour of this organism becomes very significant to both heat and cold treatments that form an integral part of food chain. Earlier studies have shown that $L$. monocytogenes is completely destroyed when food is cooked for upto and more than 2 mins to an internal temperature of $70^{\circ} \mathrm{C} .{ }^{30} \mathrm{It}$ was also reported that cultures of $L$. monocytogenes exhibited heat resistance and HTST pasteurization process for liquid egg products may not ensure a product free from Listeria $^{31}$.

The $D$-values recorded in present study (Table 5) were lower to those reported in earlier studies $^{32}$. In the case of whole milk, the values ranged from 4.6 to 5.0 at $58^{\circ} \mathrm{C}$, a trend that was comparable with an earlier study that recorded a $D$-value of $4.8 .{ }^{33}$ Contrastingly, in skim milk, the $D$-values at $56^{\circ} \mathrm{C}$ across the test cultures of Listeria spp. ranged from 6.3 to 8.4 , which was slightly lower to those values reported in earlier studies. ${ }^{34}$ On the other hand, in $\mathrm{BHI}$ broth, the $D$-values at $60^{\circ} \mathrm{C}$ ranged between 4.1 and 7.0 that were higher to the values of 0.83 to 1.28 at $60^{\circ} \mathrm{C}$ reported by Juneja et al. ${ }^{9}$ There have been two insights from the heat resistance of L. monocytogenes in discrete heating media as influenced by growth temperatures that the highest heat resistance was of a greater value at higher incubation temperatures and that the value of these differences is determined by the composition and $\mathrm{pH}$ of heating menstra. ${ }^{35}$

The variations in $D$-values observed between present study and those of earlier researchers can be associated with either one or many of these mentioned reasons: (i) phenotypic and genotypic differences in the species and strains of Listeria spp. included in studies, (ii) nature of experimental design, (iii) physiology of the cells when subjected to heat treatments, (iv) qualitative and quantitative constituents of heating media and (v) extrinsic and intrinsic factors and variables.

The survivor curve in this study followed a linear pattern. Although Listeria are known to survive pasteurization conditions, the findings of present study did indicate that a hypothetical pasteurization process of $62.8^{\circ} \mathrm{C}$ for $30 \mathrm{~min}$ for any of the heating menstra studied including skim milk and whole milk would be sufficient to eliminate the microorganism with a wide safety margin. Heat resistance of $L$. monocytogenes studied in culture broth at 55,60 and $65^{\circ} \mathrm{C}$ using three physiological states of the culture revealed that thermal tolerance could be increased with a sub-lethal heat shock resulting in heat resistant cells. ${ }^{36}$

It is of general opinion that matrix of the heating medium would greatly influence thermal resistance of the cultures being studied and more so act as insulators of heat. However, in the present study, no variation in thermal resistance was evidenced across the media and 
cultures tested. It was evident in an earlier study that diversity among strains of $L$. monocytogenes should be considered by food processors by taking in to account risk assessment and process calculations. ${ }^{37}$ In assessing the risk involved due to L. monocytogenes in the food chain, it becomes very much necessary to evaluate the nature of prevailing strains and the constituents of food that could influence the thermal resistance of microorganisms.

In the background of global emphasis on microbial food safety, the behavioral aspects related to $L$. monocytogenes need to be studied at low temperatures, particularly from the point of contamination in food industry. ${ }^{16}$ The present study revealed a significant increase in the
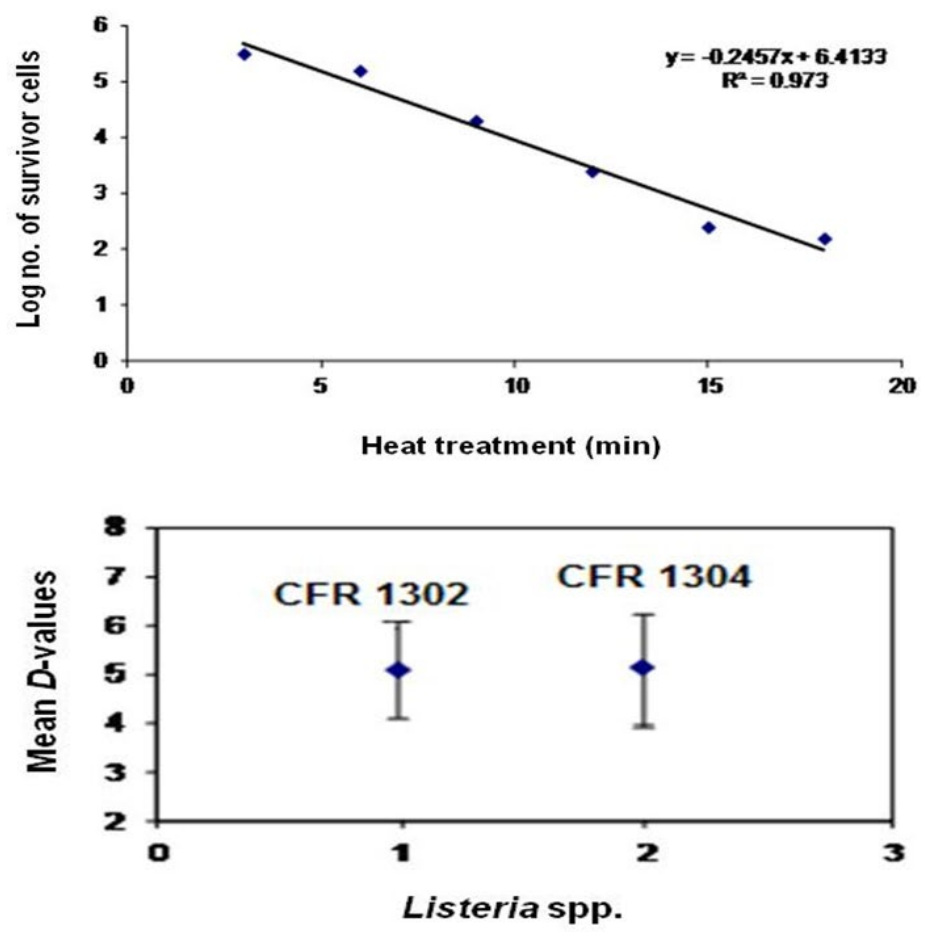

(b)

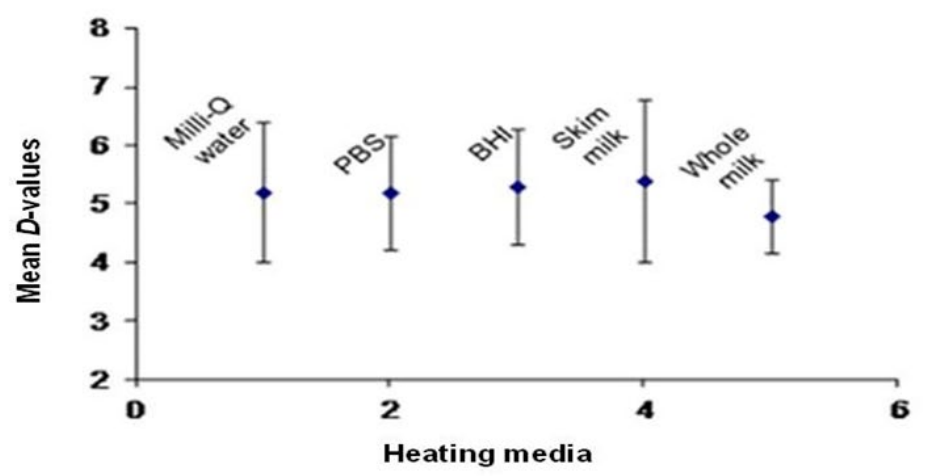

(c)

Fig. 5. Effect of heat treatment on native food isolates of Listeria monocytogenes and Listeria innocua. (a), representative survivor curve for $L$. monocytogenes CFR 1302 in Milli-Q water at 600C; (b), mean $D$-values for $L$. monocytogenes CFR 1302 and L. innocua CFR 1304; (c), mean D-values obtained for L. monocytogenes CFR 1302 and L. innocua CFR 1304 in five heating menstra at $60^{\circ} \mathrm{C}$. 
viable numbers of native toxigenic culture of $L$. monocytogenes CFR 1302 at 4 and $8^{\circ} \mathrm{C}$ during storage period, while it was only a marginal increase at $-20^{\circ} \mathrm{C}$ (Fig. 6). Even the non-toxigenic culture of L. innocua CFR 1304 showed almost same behavioral pattern under the influence of cold treatments (Fig. 7). An observation similar to that of present study with an increase in viable population of $L$. monocytogenes was recorded at 4 and $8^{\circ} \mathrm{C}$ in an earlier study. The increased

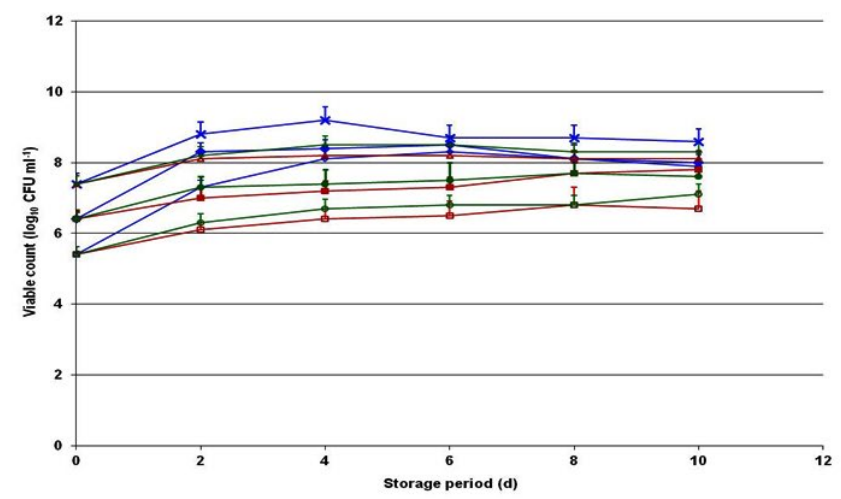

(a)

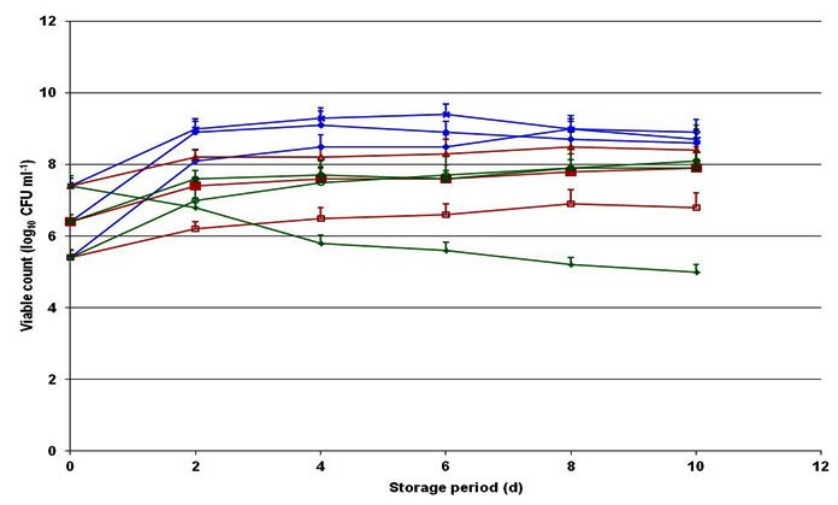

(b)

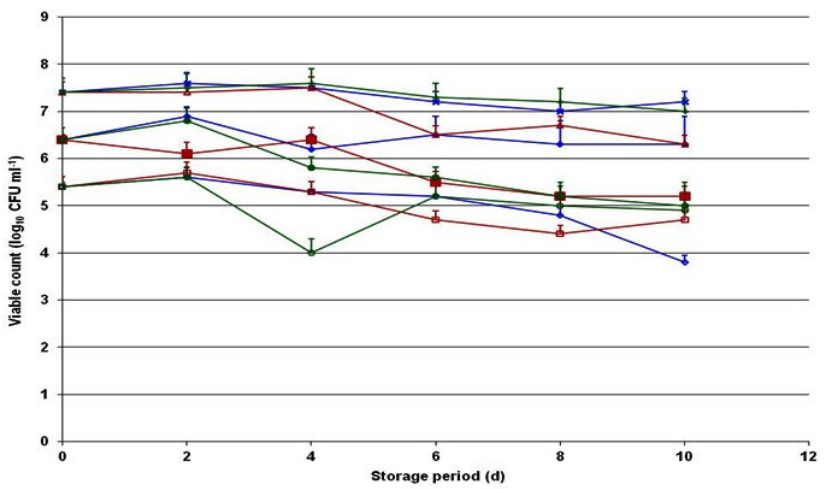

(c)

Fig. 6. Behavioral pattern of Listeria monocytogenes CFR 1302 during storage at $4^{\circ} \mathrm{C}(\mathrm{a}), 8^{\circ} \mathrm{C}(\mathrm{b})$ and $-20^{\circ} \mathrm{C}(\mathrm{c})$ in brain heart infusion broth, skim milk and whole milk introduced at initial population levels of $5.4,6.4$ and $7.4 \log _{10}$

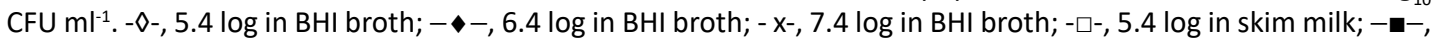

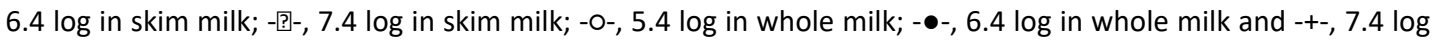
in whole milk. 
population remained to be unaltered for almost $22 \mathrm{~d}$ of storage. ${ }^{38}$

As it was in case of heat treatment studies, even the effectiveness of cold treatment in causing injury and death of $L$. monocytogenes appear to be dependent upon the type of cultures and suspending menstra. The behavior of $L$. monocytogenes in the range of low temperatures used commonly for storage revealed a faster growth rate below $10^{\circ} \mathrm{C} .{ }^{15}$

Given that food is commonly refrigerated to increase its shelf life, there have been studies about the alterations that occur in the composition of the membrane of $L$. monocytogenes at low

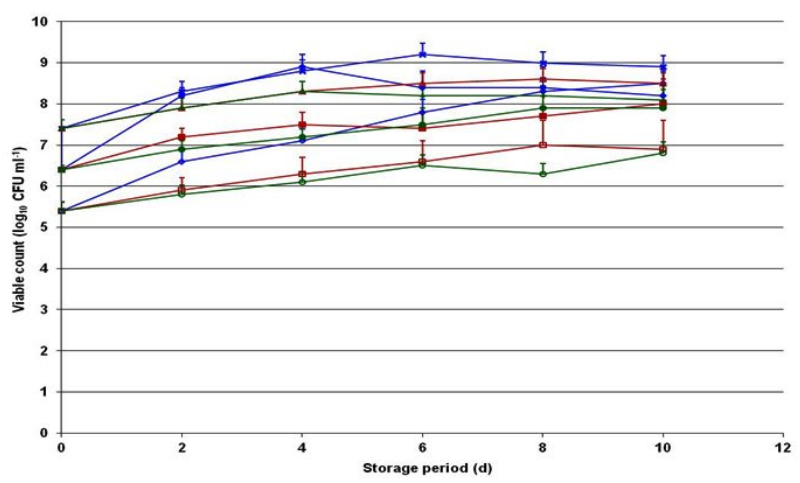

(a)

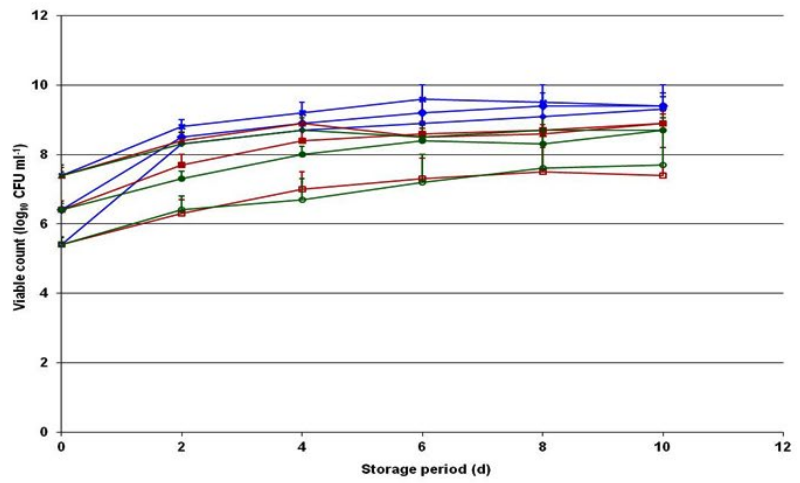

(b)

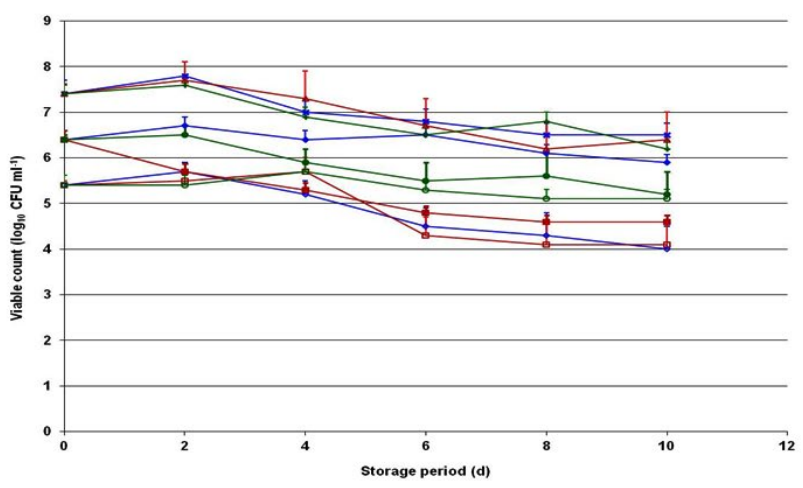

(c)

Fig. 7. Behavioral pattern of Listeria innocua CFR 1304 during storage at $4^{\circ} \mathrm{C}(\mathrm{a}), 8^{\circ} \mathrm{C}(\mathrm{b})$ and $-20^{\circ} \mathrm{C}$ (c) in brain heart infusion broth, skim milk and whole milk introduced at initial population levels of 5.4, 6.4 and $7.4 \log _{10} \mathrm{CFU} \mathrm{ml}^{-1}$. $-\diamond-, 5.4$ log in BHI broth; - -, 6.4 log in BHI broth; - x-, 7.4 log in BHI broth; - --, 5.4 log in skim milk; -,- 6.4 log in skim milk; -? ?-, 7.4 log in skim milk; -0-, 5.4 log in whole milk; -•-, 6.4 log in whole milk and -+-, 7.4 log in whole milk. 
temperatures: a degree of unsaturated fatty acids enhances the membrane fluidity at low temperatures. L. monocytogenes also creates cold shock proteins at lower temperatures by synthesizing cold acclimation proteins at a phase of balanced growth. ${ }^{39}$ There is much evidence to suggest that $L$. monocytogenes accumulates convenient solutes like carnitine, betaine, and glycine that act as cryoprotectants and enables growth of the culture at low temperature ${ }^{40}$. Being a psychrotroph in its habitat, L. monocytogenes as a foodborne pathogen has developed mechanisms to survive low temperature.

Based on the findings of this study and those reports from earlier studies, it could be inferred that refrigeration storage $\left(0\right.$ to $\left.10^{\circ} \mathrm{C}\right)$ does not ensure a complete growth inhibition of L. monocytogenes. However, refrigerated storage enables to extend the lag period and in turn reduce the growth rate. These effects may achieve significance with lower storage temperatures.

\section{CONCLUSION}

The native toxigenic $L$. monocytogenes CFR 1302 has the potential to reach higher viable population in selected culture broths as well as prevail in heat and cold treatments. Assessing the influencing factors as well as heat and cold treatments that could predict viable populations of $L$. monocytogenes as a cause of risk of health hazard in the food chain is of significance in providing safe and healthy food to human population.

\section{ACKNOWLEDGMENTS}

The authors are thankful to Director, CSIR-CFTRI, Mysore for providing the facilities for the present work. The authors are grateful to University Grants Commission, New Delhi and University of Mysore, Mysore for awarding the Faculty Support Fellowship.

\section{CONFLICT OF INTEREST}

All authors declare that there is no conflict of interest.

\section{AUTHORS' CONTRIBUTION}

JSH carried out experiment, wrote and edited the manuscript. VMC Supervised, designed and reviewed the manuscript.

\section{FUNDING}

None.

\section{DATA AVAILABILITY}

The datasets generated and/or analysed during the current study are available from the corresponding author on reasonable request.

\section{ETHICS STATEMENT}

Not applicable.

\section{REFERENCES}

1. Jayanth HS, Varadaraj MC. Survival of a native toxigenic isolate of Listeria monocytogenes CFR 1302 during storage of milk-based foods can be a potential cause of health risk. Food Sci Technol Int. 2017;23(5):426-436. doi: $10.1177 / 1082013217698329$

2. Fung $\mathrm{F}$, Wang H-S, Menon S. Food safety in the 21st century. Biomedical J. 2018;41(2):88-95. doi: 10.1016/j.bj.2018.03.003

3. FAO/WHO. Risk assessment of Listeria monocytogenes in ready-to-eat foods: Interpretative summary. Joint publication of FAO; 2004. URL https://www.fao.org/3/ y5393e/y5393e.pdf

4. Koutsoumanis KP, Taoukis S, Nychas GJE. Development of safety monitoring and assurance system for chilled food products. Int J Food Microbiol. 2005;100(13):253-260. doi: 10.1016/j.ijfoodmicro.2004.10.024

5. Buchanan RL, Phillips JG. Response surface model for predicting the effects of temperature $\mathrm{pH}$, sodium chloride content, sodium nitrite concentration and atmosphere on the growth of Listeria monocytogenes. J Food Protect. 1990;53(5):370-376. doi: 10.4315/0362028X-53.5.370

6. Koutsoumanis KP, Sofos JN. Effect of inoculum size on the combined temperature, $\mathrm{pH}$ and aw limits for growth of Listeria monocytogenes. Int J Food Microbiol. 2005;104(1):83-91. doi: 10.1016/j. ijfoodmicro.2005.01.010

7. Skandamis PN, Stopforth JD, Yoon Y, Kendall PA, Sofos $J N$. Modeling the effect of storage atmosphere on growth-no-growth interface of Listeria monocytogenes as a function of temperature, sodium lactate, sodium diacetate and $\mathrm{NaCl}$. J Food Protect. 2007;70(10):23292338. doi: 10.4315/0362-028X-70.10.2329

8. Axelsson L, Bjerke GA, McLeod A, Bergetl, Holck AL. Growth behavior of Listeria monocytogenes in a traditional Norwegian fermented fish product (Rakfish), and its inhibition through bacteriophage addition. Foods. 2020;9(2):119. doi: 10.3390/ foods9020119

9. Juneja VK, Foglia TA, Marmer BS. Heat resistance and fatty acid composition of Listeria monocytogenes: Effect of $\mathrm{pH}$, acidulant, and growth temperature. J Food Protect. 1998;61(6):683-687. doi: 10.4315/0362-028X61.6 .683

10. Doyle ME, Mazzotta AS, Wang T, Wiseman DW, Scott VN. Heat resistance of Listeria monocytogenes. J Food Protect. 2001;64(3):410-429. doi: 10.4315/0362-028X- 


\subsubsection{0}

11. Murphy RY, Beard BL, Martin EM, Duncan LK, MarcyJA. Comparative study of thermal inactivation of Escherichia coli 0157:H7, Salmonella, and Listeria monocytogenes in ground pork. J Food Sci. 2004;69(4):FMS97-FMS101. doi: 10.1111/j.13652621.2004.tb06351.x

12. Azizoglu RO, Osborne J, Wilson S, Kathariou S. Role of growth temperature in freeze thaw tolerance of Listeria spp. Appl Environ Microbiol. 2009;75(16):53155320. doi: 10.1128/AEM.00458-09

13. Lin MH, Chiang ML, Pan CL, Chou CC. Heat shock and cold shock treatments affect the survival of Listeria monocytogenes and Salmonella typhimurium exposed to disinfectants. J Food Protect. 2012;75(4):695-700. doi: 10.4315/0362-028X.JFP-11-419

14. Tsai H-C, Taylor MH, Song X, Sheng L, Tang J, Zhu MJ. Thermal resistance of Listeria monocytogenes in natural unsweetened cocoa powder under different water activity. Food Control. 2019;102:22-28. doi: 10.1016/j.foodcont.2019.03.006

15. Bajard S, Rosso L, Fardel G, Fandrois JP. The particular behavior of Listeria monocytogenes under sub-optimal conditions. Int J Food Microbiol. 1996;29(2-3):201-211. doi: 10.1016/0168-1605(95)00031-3

16. Membre JM, Ross T, McMeekin T. Behavior of Listeria monocytogenes under combined chilling process. Lett Appl Microbiol. 1999;28(3):216-220. doi:10.1046/ j.1365-2672.1999.00499.x

17. Magalhaes R, Ferreira V, Brandao TRS, Casqueta Palencia R, Almeida G, Teixeira P. Persistent and nonpersistent strains of Listeria monocytogenes: a focus on growth kinetics under different temperature, salt, and $\mathrm{pH}$ conditions and their sensitivity to sanitizers. Food Microbiol. 2016;57:103-108. doi: 10.1016/j.fm.2016.02.005

18. Diakogiannis I, Proestos C, Varzakas T, Markakki P. Survival of Listeria monocytogenes in Tomato juice at 5 and $30^{\circ} \mathrm{C}$ storage. Curr Res Nutr Food Sci J. 2017;5(1):01-05. doi: 10.12944/CRNFSJ.5.1.01

19. Hingston PA, Hansen LT, Pombert J-F, Wang S. Characterization of Listeria monocytogenes enhanced cold-tolerance variants isolated during prolonged cold storage. Int J Food Microbiol. 2019;306:108262. doi:10.1016/j.ijfoodmicro.2019.108262

20. Rocourt J, BenEmbarek P, Toyofuku H, Schlundt J. Quantitative risk assessment of Listeria monocytogenes in ready-to-eat foods: the FAO/WHO approach. doi: 10.1016/S0928-8244(02)00468-6

21. USFDA; 2001. https://www.fda.gov/food/laboratorymethods-food/bam-r60-001-m-phosphate-bufferedsaline-ph-75

22. Bechmann IE, Jensen HS, Beknaes N, Warm K, Nielsen J. Prediction of chemical, physical and sensory data from process parameters for frozen cod using multivariate analysis. J Sci Food Agric. 1998;78(3):329-336. doi:10.1002/(SICI)1097-0010(199811)78:3<329::AID JSFA121>3.0.CO;2-E

23. Ostle B, Malone LC. Statistics in research: basic concepts and techniques for research workers. 4th edn. lowa, USA: lowa State Press; 1988.
24. Bolton DJ, McMahon CM, Doherty AM, et al. Thermal inactivation of Listeria monocytogenes and Yersinia enterocolitica in minced beef under laboratory conditions and in sous-vide prepared minced and solid beef cooked in a commercial retort. J Appl Microbiol. 2000;88(4):626-632. doi: 10.1046/j.13652672.2000.01001.x

25. Desai SV, Varadaraj MC. Behavioral pattern of vegetative cells and spores of Bacillus cereus as affected by time-temperature combination used in processing of Indian traditional foods. J Food Sci Technol. 2010;47(5):549-556. doi: 10.1007/s13197010-0099-9

26. Capita R, Alonso-Calleja C, Garcia-Fernandez MC, Moreno B. Comparison of the efficacy of different techniques, culture media, and sources of blood in determining the haemolytic activity of Listeria spp. Can J Microbiol. 2001;47(7):653-661. doi: 10.1139/ w01-054

27. Hefnawy YA, Marth EH. Survival and growth of Listeria monocytogenes in broth supplemented with sodium chloride and held at 4 and $13^{\circ} \mathrm{C}$. LWT-Food Sci Technol. 1993;26(5):388-392. doi: 10.1006/fstl.1993.1077

28. Guillier L, Augustin JC. Modeling the individual cell lag time distributions of Listeria monocytogenes as a function of the physiological state and the growth conditions. Int J Food Microbiol. 2006;111(3):241-251. doi: 10.1016/j.ijfoodmicro.2006.05.011

29. Razavilar V, Genigeorgis C. Prediction of Listeria growth as affected by various levels of chemicals, $\mathrm{pH}$, temperature and storage time in a model broth. Int J Food Microbiol. 1998;40(3):149-157. doi: 10.1016/ S0168-1605(98)00014-2

30. Mackey BM, Bratchell N. The heat resistance of Listeria monocytogenes. Lett App/ Microbiol. 1989;9(3):89-94. doi: 10.1111/j.1472-765X.1989.tb00298.x

31. Bartlett FM, Hawke AE. Heat resistance of Listeria monocytogenes Scott A and HAL 957E1 in various liquid egg products. J Food Protect. 1995;58(11):12111214. doi: 10.4315/0362-028X-58.11.1211

32. Sorqvist $\mathrm{S}$. Heat resistance of different serovars of Listeria monocytogenes. J Appl Bacteriol. 1994;76(4):383-388. doi: 10.1111/j.1365-2672.1994. tb01644.x

33. Bradshaw JG, Peeler JT, Twedt RM. Thermal resistance of Listeria spp. in milk. J Food Protect. 1991;54(1):1214. doi: $10.4315 / 0362-028 X-54.1 .12$

34. Fairchild TM, Foegeding PM. A proposed nonpathogenic biological indicator for thermal inactivation of Listeria monocytogenes. Appl Environ Microbiol. 1993;59(4):1247-1250. doi: 10.1128/aem.59.4.12471250.1993

35. Pagan R, Manas P, Avarez I, Sala F. Heat resistance in different heating media of Listeria monocytogenes ATCC 15313 grown at different temperatures. J Food Safety. 1998;18(3):205-290. doi: 10.1111/j.17454565.1998.tb00215.x

36. Augustin JC, Carlier V, Rozier J. Mathematical modelling of the heat resistance of Listeria monocytogenes. J Appl Microbiol. 1998;84(2):185-191. doi: 10.1046/j.13652672.1998.00317.x 
37. Jesus AJD, Whiting RC. Thermal inactivation, growth and survival studies of Listeria monocytogenes strains belonging to three distinct genotypic lineages. J Food Protect. 2003;66(9):1611-1617. doi: 10.4315/0362028X-66.9.1611

38. Rosenow EM, Marth EH. Growth of Listeria monocytogenes in skim, whole and chocolate milk, and in whipping cream during incubation at 4, 8, 13, 21 and $35^{\circ} \mathrm{C}$. J Food Protect. 1987;50(6):452-459. doi: 10.4315/0362-028X-50.6.452
39. Bayles DO. Changes in heat resistance resulting from $\mathrm{pH}$ and nutritional shifts of acid-adapted and nonacid-adapted Listeria monocytogenes Scott A. J Food Protect. 2004;67(2):316-321. doi: 10.4315/0362-028X67.2.316

40. Gandhi M, Chikindas ML. Listeria: A foodborne pathogen that knows how to survive. Int J Food Microbiol. 2007;113(1):1-15. doi: 10.1016/j. ijfoodmicro.2006.07.008 